\title{
An easy-to-use scoring system to estimate the survival of patients irradiated for bone metastases from lung cancer
}

\author{
Dirk Rades ${ }^{1}$, Rapha Haus ${ }^{1}$, Stefan Janssen ${ }^{1}$, Steven E. Schild ${ }^{2}$ \\ ${ }^{1}$ Department of Radiation Oncology, University of Lübeck, Lübeck, Germany; ${ }^{2}$ Department of Radiation Oncology, Mayo Clinic, Scottsdale, AZ, USA \\ Contributions: (I) Conception and design: All authors; (II) Administrative support: D Rades; (III) Provision of study materials or patients: D Rades, R \\ Haus, S Janssen; (IV) Collection and assembly of data: D Rades, R Haus, S Janssen; (V) Data analysis and interpretation: D Rades, SE Schild; (VI) \\ Manuscript writing: All authors; (VII) Final approval of manuscript: All authors. \\ Correspondence to: Prof. Dr. med. Dirk Rades. Chair of the Department of Radiation Oncology, University of Lübeck, Ratzeburger Allee 160,23562 \\ Lübeck, Germany. Email: rades.dirk@gmx.net.
}

\begin{abstract}
Background: The remaining lifespan of patients with metastatic lung cancer should be considered when designing a personalized treatment program. To facilitate the estimation survival in lung cancer patients with bone metastases, a specific scoring system was created.

Methods: One-hundred-and-fifty-three patients receiving fractionated radiotherapy for bone metastases without spinal cord compression from lung cancer were included in this retrospective study. Age, gender, Eastern Cooperative Oncology Group (ECOG) performance score, histology, interval from lung cancer diagnosis until irradiation of bone metastases, visceral metastases, additional bone metastases, type and number of irradiated sites, pathological fracture, upfront surgery and previous systemic treatment were evaluated for potential associations with survival. Those factors that were significant $(\mathrm{P}<0.05)$ or showed a trend $(\mathrm{P} \leq 0.10)$ on multivariate analysis were used to create the scoring system.
\end{abstract}

Results: On multivariate analysis, ECOG performance score was significant (risk ratio: $2.77, \mathrm{P}<0.001$ ), and age showed a trend (risk ratio: $1.34, \mathrm{P}=0.10$ ). The following scoring points were assigned: age $\leq 65$ years $=1$ point, age $\geq 66$ years $=0$ points, ECOG performance score of $0-1=1$ point, and ECOG performance score of $\geq 2=0$ points. Three prognostic groups were obtained: 0 points $(n=38), 1$ point $(n=71)$ and 2 points $(n=44)$. Six-month survival rates were $21 \%, 41 \%$ and $75 \%, 12$-month survival rates $7 \%, 27 \%$ and $56 \%(\mathrm{P}<0.001)$.

Conclusions: This scoring system can help estimate the remaining lifespan of lung cancer patients to be irradiated for bone metastases and will contribute to the personalization of their treatment.

Keywords: Non-small cell lung cancer; bone metastases; irradiation; survival; scoring system

Submitted Dec 06, 2019. Accepted for publication Mar 02, 2020.

doi: $10.21037 /$ tlcr-19-642

View this article at: http://dx.doi.org/10.21037/tlcr-19-642

\section{Introduction}

In patients with bone metastases, lung cancer is one of the most frequent primary tumors (1). To administer optimal care for individuals with bone metastases from lung cancer, personalized treatment programs are very important. Since many of these patients receive radiotherapy, these programs often include a choice of the most appropriate radiation regimen. Radiation regimens used for treating of bone metastases range from single-fraction to longer-course multi-fraction programs lasting weeks (2). When choosing a personalized radiation regimen, several aspects should be considered including the indication for radiotherapy and the patient's remaining lifespan. In case of uncomplicated painful bone metastases, a single fraction of radiotherapy is as effective as multi-fraction radiotherapy in achieving pain relief (3-7). However, single-fraction radiotherapy is less effective than multi-fraction programs with respect to 
Table 1 Distribution of the factors evaluated for a potential impact on survival

\begin{tabular}{|c|c|}
\hline Factor & $\mathrm{N}$ patients [\%] \\
\hline \multicolumn{2}{|l|}{ Age } \\
\hline$\leq 65$ years & $77[50]$ \\
\hline$\geq 66$ years & $76[50]$ \\
\hline \multicolumn{2}{|l|}{ Gender } \\
\hline Female & $66[43]$ \\
\hline Male & $87[57]$ \\
\hline \multicolumn{2}{|c|}{ ECOG performance score } \\
\hline $0-1$ & $83[54]$ \\
\hline$\geq 2$ & $70[46]$ \\
\hline \multicolumn{2}{|l|}{ Histology } \\
\hline SCLC & $21[14]$ \\
\hline NSCLC & $132[86]$ \\
\hline \multicolumn{2}{|c|}{$\begin{array}{l}\text { Interval from diagnosis of lung cancer until } \\
\text { irradiation of bone metastases }\end{array}$} \\
\hline$\leq 2$ months & $92[60]$ \\
\hline$\geq 3$ months & $61[40]$ \\
\hline \multicolumn{2}{|c|}{ Visceral metastases } \\
\hline No & $56[37]$ \\
\hline Yes & 97 [73] \\
\hline \multicolumn{2}{|c|}{ Additional bone metastases } \\
\hline No & $37[24]$ \\
\hline Yes & $116[76]$ \\
\hline \multicolumn{2}{|c|}{ Site(s) of irradiated bone metastases } \\
\hline Spine & $55[36]$ \\
\hline Extra-spinal & 56 [37] \\
\hline Both & $42[27]$ \\
\hline \multicolumn{2}{|c|}{ Number of irradiated metastatic sites } \\
\hline 1 & $70[46]$ \\
\hline$\geq 2$ & $83[54]$ \\
\hline \multicolumn{2}{|c|}{ Pathological fracture } \\
\hline No & $118[77]$ \\
\hline Yes & 35 [23] \\
\hline \multicolumn{2}{|c|}{ Upfront surgery } \\
\hline No & $124[80]$ \\
\hline Yes & 29 [20] \\
\hline \multicolumn{2}{|c|}{ Previous systemic treatment } \\
\hline No & $72[47]$ \\
\hline Yes & $81[53]$ \\
\hline
\end{tabular}

ECOG, Eastern Cooperative Oncology Group. longer-term symptom control, particularly when compared longer-course programs. Longer-course multi-fraction radiotherapy resulted in significantly better recalcification of the osteolytic bone than single-fraction treatment in a randomized trial (8). Since the risk of local failure increases with lifetime, patients with bone metastases and favorable survival prognoses can benefit from longercourse radiotherapy programs. In contrast, patients with a poor survival prognosis, who likely will die before local recurrence, are good candidates for single-fraction radiotherapy (2). These considerations illustrate that it is very important to take into account a patient's remaining survival time when designing a personalized treatment approach.

Prediction of individual survival prognoses can be considerably facilitated with the use of scoring systems. To achieve the best possible personalization of the treatment for patients with bone metastases, specific scoring systems are desirable for each primary tumor with metastatic spread to the bone including lung cancer. The concept of developing specific survival scores for lung cancer patients irradiated for metastatic disease has already been realized for patients with brain metastases and patients with metastatic epidural spinal cord compression (9-11). The current study was performed to create a specific survival score for lung cancer patients irradiated for bone metastases.

\section{Methods}

A total of 153 patients who received fractionated radiotherapy for bone metastases without spinal cord compression from lung cancer between January 2009 and April 2019 were included in this retrospective study. Twelve factors (Table 1) were evaluated for a potential impact on survival including age ( $\leq 65$ vs. $\geq 66$ years, median age: 65 years), gender, Eastern Cooperative Oncology Group (ECOG) performance score (0-1 vs. $\geq 2$ ), histology (SCLC $v s$. NSCLC), interval from first diagnosis of lung cancer until irradiation of bone metastases ( $\leq 2 v s . \geq 3$ months, median interval: 2 months), visceral metastases at the time of radiotherapy (no vs. yes), additional bone metastases (no $v s$. yes), site(s) of irradiated bone metastases (spine vs. extraspinal $v s$. both), number of irradiated metastatic sites (1 $v s . \geq 2$ ), pathological fracture (no $v s$. yes), upfront surgery of irradiated bone metastases (no vs. yes), and previous systemic treatment (no vs. yes). 
Patients included in this study had complete data regarding the twelve investigated potential prognostic factors and survival. In order to reduce a selection bias due to the dose-fractionation regimen of radiotherapy, only patients treated with multi-fraction longer-course radiotherapy (the standard regimen in the centers participating in this study) were included. The dosefractionation regimens were either $10 \times 3$ Gy over 2 weeks $(\mathrm{n}=76), 12 \times 3-13 \times 3$ Gy over 2.5 weeks $(\mathrm{n}=4), 14 \times 2-15 \times 2$ Gy over 3 weeks $(\mathrm{n}=12), 14 \times 2.5-15 \times 2.5$ Gy over 3 weeks $(\mathrm{n}=49)$ or $18 \times 2-20 \times 2$ Gy over $2.5-3$ weeks $(n=12)$.

Time to death has been calculated from the first day of radiotherapy. Univariate analyses of survival were performed with the Kaplan-Meier-method and the log-rank test. The potential prognostic factors that were significantly $(\mathrm{P}<0.05)$ associated with survival on univariate analyses were subsequently included in a Cox regression analysis. Those factors that were significant $(\mathrm{P}<0.05)$ or showed a trend $(\mathrm{P} \leq 0.10)$ in the Cox regression analysis were used to create the scoring system for estimation of survival.

All procedures performed were in accordance with ethical standards and the Helsinki declaration from 1964 as revised in 2013. The study was approved by an institutional review board (IRB), namely the Ethics Committee of the University of Lübeck, (reference number 18-254A). Due to its retrospective design, informed consent specifically for this study was not required by the IRB. For protection of to the patient's personal data, only anonymized data have been used for the analyses of this study.

\section{Results}

Median follow up times were 5 months (range, 0-155 months) in the entire cohort and 13 months (range, 4-155 months) in those patients who were still alive at the last follow up. In the entire cohort, the survival rates were $59 \%, 46 \%, 36 \%$ and $30 \%$, respectively, at 3, 6, 9 and 12 months. On univariate analysis, age $\leq 65$ years $(\mathrm{P}=0.017)$ and an ECOG performance score of $0-1(\mathrm{P}<0.001)$ were significantly associated with survival. The results of the complete univariate analyses are summarized in Table 2. In the Cox regression analysis, ECOG performance score remained significant (risk ratio: $2.77,95 \%$ confidence interval: $1.93-4.00, \mathrm{P}<0.001$ ), and age showed a trend (risk ratio: $1.34,95 \%$ confidence interval: $0.94-1.89, \mathrm{P}=0.10$ ).

Both factors were used to create the scoring system for estimation of survival. The following scoring points were assigned: age $\leq 65$ years $=1$ point, age $\geq 66$ years $=0$ points, ECOG performance score of $0-1=1$ point, and ECOG performance score of $\geq 2=0$ points. Thus, three prognostic groups were obtained, i.e. 0 points $(n=38), 1$ point $(n=71)$ and 2 points $(n=44)$. The survival rates of these groups at 3, 6, 9 and 12 months are summarized in Table 3, and the corresponding Kaplan-Meier curves are given in Figure 1.

\section{Discussion}

The survival prognoses of patients irradiated for bone metastases vary between a few weeks and several years. This should be taken into account when tailoring a treatment regimen to an individual patient. Patients with uncomplicated painful bone metastases, i.e., without a pending or existing pathological fracture, metastatic epidural spinal cord compression or an extensive soft-tissue component, and a short survival time appear optimally treated with single-fraction radiotherapy such as $1 \times 8 \mathrm{~Gy}$ or $1 \times 10$ Gy (2-7). This regimen would allow the patients to spend more time without treatment for other important issues. Reviews and meta-analyses of randomized trials demonstrated single-fraction radiotherapy to be as effective in relieving pain as multi-fraction radiation regimens (3-7). Fifteen years ago, Sze et al. presented a systematic review of 11 trials and 3,435 patients with uncomplicated painful bone metastases (6). The overall pain response rates were $60 \%$ after single-fraction and $59 \%$ after multi-fraction radiotherapy, respectively (odds ratio: 1.03, 95\% confidence interval: 0.89-1.19). Complete pain relief was achieved in $34 \%$ and $32 \%$ of the patients, respectively (odds ratio: 1.11, 95\% confidence interval: 0.94-1.30). More recently, Chow et al. presented an updated systematic review that included 25 randomized trials with a total of 5,617 patients with bone pain from uncomplicated metastases (7). Overall pain relief was achieved in $60 \%$ of patients after singlefraction radiotherapy compared to $61 \%$ after multi-fraction treatment $(\mathrm{P}=0.36)$. Complete pain relief rates were $23 \%$ and $24 \%$, respectively (7).

The systematic reviews revealed that re-treatment of the same bone metastases was required significantly more often after single-fraction than after multi-fraction radiotherapy. In the review of Sze et al., the re-treatment rates were $21.5 \%$ and $7.4 \%$, respectively (odds ratio: $3.44,95 \%$ confidence interval: 2.67-4.43) (6). In the updated review of Chow et al., the re-treatment rates were $20 \%$ and $8 \%$, respectively $(\mathrm{P}<0.00001)(7)$. Moreover, a randomized trial 
Table 2 Univariate analyses of survival rates of the 12 potential prognostic factors

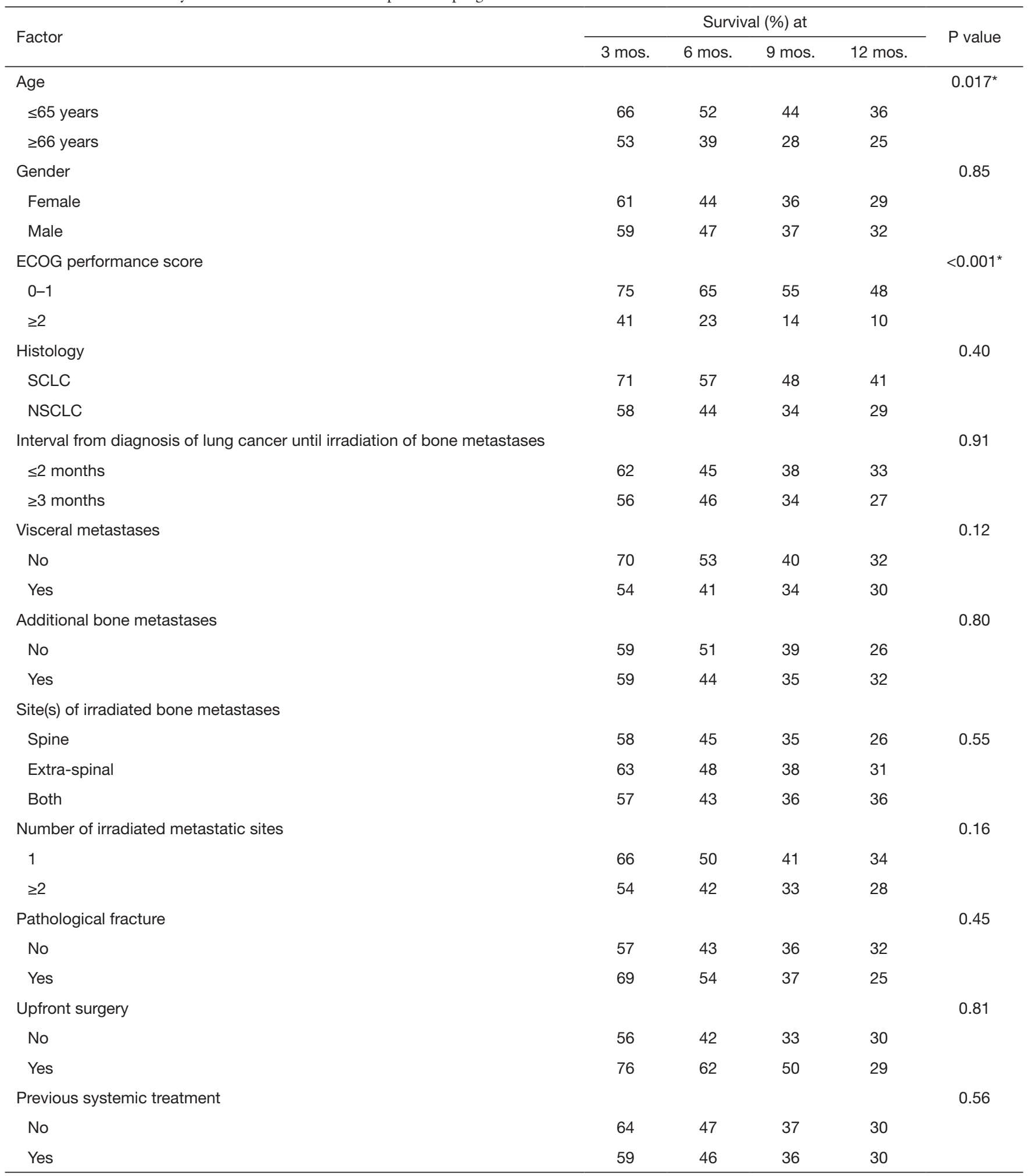

*, significant P values. ECOG, Eastern Cooperative Oncology Group. 
Table 3 Survival rates of the prognostic groups 0 points, 1 point and 2 points

\begin{tabular}{lccccc}
\hline \multirow{2}{*}{ Prognostic group } & \multicolumn{4}{c}{ Survival $(\%)$ at } & \multirow{2}{*}{ P value } \\
\cline { 2 - 5 } & 3 mos. & 6 mos. & 9 mos. & 12 mos. & \\
\hline 0 points $(n=38)$ & 37 & 21 & 11 & 7 & $<0.001^{*}$ \\
1 point $(n=71)$ & 56 & 41 & 32 & 27 & \\
2 points $(n=44)$ & 84 & 75 & 66 & 56 & \\
\hline
\end{tabular}

*, significant $P$ value.

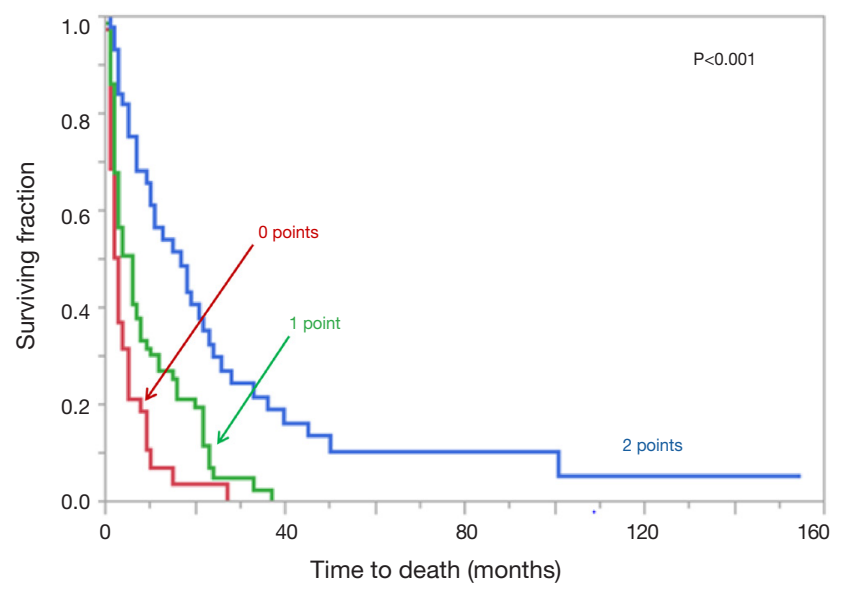

Figure 1 Kaplan-Meier curves for survival of the prognostic groups 0 points, 1 point and 2 points. The $\mathrm{P}$ value was calculated using the log-rank test.

demonstrated that re-calcification of the osteolytic bone was significantly more pronounced after $10 \times 3$ Gy over 2 weeks than after $1 \times 8$ Gy $(173 \%$ vs. $120 \%, \mathrm{P}<0.0001)(8)$. Since re-calcification takes time and can generally be expected only several months following radiotherapy, it becomes more of an issue in longer-term survivors (2). Also the risk of recurrent bone pain in the irradiated regions rises with lifetime. Therefore, patients with bone metastases and favorable survival prognoses appear better treated with multi-fraction radiotherapy. It has been shown for patients with vertebral bone metastases associated with spinal cord compression and favorable survival prognoses that radiotherapy with total doses beyond 30 Gy (e.g., $15 \times 2-15 \times 5$ Gy or $20 \times 2$ Gy) resulted in improved local control (12). If these findings can be transferred to patients with bone metastases without spinal cord compression, one may consider using longer-course radiotherapy with doses beyond 30 Gy also for long-term survivors of this group.

To be able to select the most appropriate dosefractionation regimen and to avoid over- or undertreatment, it would be very helpful if one could predict an individual patient's survival time prior to the start of treatment. A few scoring system already exist for patients irradiated for bone metastases (13-16). However, these tools were developed in cohorts of patients with many different primary tumor types. In order to account for the individual biology and other individual characteristics of a particularly tumor type, specific scoring systems for single tumor entities would be important. In the current study, a scoring system has been developed specifically for bone metastases from lung cancer. Based on the prognostic factors age and performance status, which can be assessed easily and fast, three prognostic groups were designed. Patients with 0 points had poor survival prognoses; only $37 \%$ and $21 \%$ of the patients survived for 3 and 6 months, respectively. Thus, patients of this group with symptomatic bone metastases appear good candidates for single-fraction radiotherapy. Patients with 1 point had an intermediate survival prognosis with $41 \%$ of the patients surviving for 6 months and $27 \%$ for 12 months. They may be considered for multi-fraction radiotherapy of intermediate duration, for example with $10 \times 3$ Gy. Patients with 2 points had the most favorable survival prognoses with $75 \%$ surviving for 6 months and $56 \%$ for 12 months. These patients may be candidates for longer-course radiotherapy with total doses beyond $30 \mathrm{~Gy}$. However, when considering these suggestions, one should bear in mind the retrospective design of this study. Although only patients treated with longer-course multifraction radiotherapy were included to reduce the risk of a selection bias due to the dose-fractionation regimen, the risk of hidden selection biases still exists. The findings of this study may not be applicable to patients treated with single-fraction or short-course multi-fraction irradiation, because these patients were not included. Moreover, it has to be noticed that patients with complicated bone metastases should always be considered for multi-fraction radiotherapy (2).

\section{Conclusions}

The new scoring system including three prognostic groups may help estimating the lifespan of lung cancer patients to be irradiated for bone metastases. It can be used easily and fast during clinical routine. It may be useful for physicians 
when tailoring the treatment regimen to the individual. Moreover, it can be valuable in the stratification of patients with bone metastases from lung cancer in future trials.

\section{Acknowledgments}

Funding: None.

\section{Footnote}

Conflicts of Interest: All authors have completed the ICMJE uniform disclosure form (available at http://dx.doi. org/10.21037/tlcr-19-642). DR reports personal fees from Elsevier, personal fees and non-financial support from Roche Pharma, Bristol Myers Squibb, Astra Zeneca, Bayer HealthCare, Novartis Oncology, Amgen, Janssen-Cilag, MerckSerono outside the submitted work. SES reports personal fees from Noxopharm, other from UpToDate outside the submitted work. The other authors have no conflicts of interest to declare.

Ethical Statement: The authors are accountable for all aspects of the work in ensuring that questions related to the accuracy or integrity of any part of the work are appropriately investigated and resolved. All procedures performed were in accordance with ethical standards and the Helsinki declaration from 1964 as revised in 2013. The study was approved by an institutional review board (IRB), namely the Ethics Committee of the University of Lübeck, (reference number 18-254A). Due to its retrospective design, informed consent specifically for this study was not required by the IRB. For protection of to the patient's personal data, only anonymized data have been used for the analyses of this study.

Open Access Statement: This is an Open Access article distributed in accordance with the Creative Commons Attribution-NonCommercial-NoDerivs 4.0 International License (CC BY-NC-ND 4.0), which permits the noncommercial replication and distribution of the article with the strict proviso that no changes or edits are made and the original work is properly cited (including links to both the formal publication through the relevant DOI and the license). See: https://creativecommons.org/licenses/by-nc-nd/4.0/.

\section{References}

1. Siegel RL, Miller KD, Jemal A. Cancer statistics, 2019.
CA Cancer J Clin 2019;69:7-34.

2. Rades D, Schild SE, Abrahm JL. Treatment of painful bone metastases. Nat Rev Clin Oncol 2010;7:220-9.

3. Jeremic B, Shibamoto Y, Acimovic L, et al. A randomized trial of three single-dose radiation therapy regimens in the treatment of metastatic bone pain. Int J Radiat Oncol Biol Phys 1998;42:161-7.

4. Jeremic B. Single fraction external beam radiation therapy in the treatment of localized metastatic bone pain. A review. J Pain Symptom Manage 2001;22:1048-58.

5. Dennis K, Makhani L, Zeng L, et al. Single fraction conventional external beam radiation therapy for bone metastases: a systematic review of randomised controlled trials. Radiother Oncol 2013;106:5-14.

6. Sze WM, Shelley M, Held I, et al. Palliation of metastatic bone pain: single fraction versus multifraction radiotherapy - a systematic review of the randomised trials. Cochrane Database Syst Rev 2004;2:CD004721.

7. Chow E, Zeng L, Salvo N, et al. Update on the systematic review of palliative radiotherapy trials for bone metastases. Clin Oncol (R Coll Radiol) 2012;24:112-24.

8. Koswig S, Budach V. Remineralization and pain relief in bone metastases after after different radiotherapy fractions (10 times 3 Gy vs. 1 time 8 Gy). A prospective study. Strahlenther Onkol 1999;175:500-8.

9. Rades D, Huttenlocher S, Dziggel L, et al. A new tool predicting survival after radiosurgery alone for one or two cerebral metastases from lung cancer. Lung 2015;193:299-302.

10. Rades D, Hansen HC, Janssen S, et al. Comparison of diagnosis-specific survival scores for patients with smallcell lung cancer irradiated for brain metastases. Cancers 2019;11:233.

11. Rades D, Douglas S, Veninga T, et al. A validated survival score for patients with metastatic spinal cord compression from non-small cell lung cancer. BMC Cancer 2012;12:302.

12. Rades D, Panzner A, Rudat V, et al. Dose escalation of radiotherapy for metastatic spinal cord compression (MSCC) in patients with relatively favorable survival prognosis. Strahlenther Onkol 2011;187:729-35.

13. van der Linden YM, Dijkstra SP, Vonk EJ, et al. Prediction of survival in patients with metastases in the spinal column: results based on a randomized trial of radiotherapy. Cancer 2005;103:320-8.

14. Bollen L, van der Linden YM, Pondaag W, et al. Prognostic factors associated with survival in patients with symptomatic spinal bone metastases: a retrospective cohort 
study of 1,043 patients. Neuro Oncol 2014;16:991-8.

15. Westhoff PG, de Graeff A, Monninkhof EM, et al. An easy tool to predict survival in patients receiving radiation therapy for painful bone metastases. Int $\mathrm{J}$ Radiat Oncol Biol Phys 2014;90:739-47.

Cite this article as: Rades D, Haus R, Janssen S, Schild SE. An easy-to-use scoring system to estimate the survival of patients irradiated for bone metastases from lung cancer. Transl Lung Cancer Res 2020;9(4):1067-1073. doi: 10.21037/tlcr-19-642
16. Willeumier JJ, van der Linden YM, van der Wal CWPG, et al. An easy-to-use prognostic model for survival estimation for patients with symptomatic long bone metastases. J Bone Joint Surg Am 2018;100:196-204. 